\title{
Libertad a costa de protección constitucional: inmigrantes indocumentados y los derechos de la Cuarta Enmienda
}

\author{
Linet Suárez*
}

Resumen. - La Corte Suprema ha formulado una serie de opiniones que tratan indirectamente sobre los derechos de la Cuarta Enmienda de los inmigrantes indocumentados. Sin embargo, ninguna de esas opiniones responde las preguntas que más valen: ¿los inmigrantes indocumentados se benefician de las protecciones de la Cuarta Enmienda?, y si lo hacen, ¿cuáles son? Estas preguntas se han convertido significativamente más importantes porque los avances tecnológicos facilitan búsquedas y registros intrusivos por parte de los agentes encargados de hacer cumplir la ley. Este artículo se va a focalizar específicamente en el Departamento de Seguridad Nacional y el uso de los brazaletes de tobillo con GPS para monitorear a los inmigrantes indocumentados. Asimismo, se compara las opiniones de la Corte Suprema con respecto de los inmigrantes indocumentados y los derechos de la Cuarta Enmienda en la era tecnológica. Actualmente, es más importante que nunca encontrar cierta claridad legal si planeamos alguna vez responder qué tan lejos es muy lejos.

\begin{abstract}
The Supreme Court has announced a series of opinions which address, in an indirect form, the undocumented immigrants' Fourth Amendment rights. However, none of these opinions are the answer to the most valuable questions: do the undocumented immigrants benefit from the Fourth Amendment's legal protection? and if they do, which ones are they? These inquiries have gained significant importance because of the technological development that facilitates searches and intrusive registrations from the agents in charge of fulfilling the law. This article will have as a main focus the Department of Homeland Security and the use of GPS ankle bracelets to keep undocumented immigrants under observation. Furthermore, there will be a comparison of the Supreme Court's opinions regarding the undocumented immigrants and the Fourth Amendment's rights in a technological era. Nowadays, it is more important than ever to find some legal clarity if we ever plan to answer how far is too far.
\end{abstract}

* Linet Suárez Bachiller en Ciencia Política por el Bryn Mawr College (2013) y Juris Doctor por el University of Miami School of Law (2017).

* La autora agradece a la profesora Elizabeth Iglesias por su inspiración en el tema. Asimismo, dedica este artículo a su madre, Tatiana Alvarez, quien, sin sus sacrificios desinteresados, la autora no habría cumplido su propio "sueño americano".

* Traducción libre a cargo de Diego Quesada Nicoli y Stephanie Torres García, ex miembros del Consejo Directivo de Forseti. 


\section{Introducción}

La Estatua de la Libertad tiene grabadas las palabras "give me your tired, your poor, your huddled masses yearning to breathe free" pero omite diplomáticamente cualquier mención al sometimiento de estas masas a búsquedas estatales intrusivas ${ }^{1}$. Sería más adecuado para Lady Liberty agregar que la libertad puede venir a costa de la privacidad.

Actualmente, más de nueve millones de inmigrantes indocumentados se encuentran viviendo en los Estados Unidos y entre medio y un millón más llegan cada año². El Congreso frecuentemente crea leyes para regular la inmigración, pero esas leyes afectan negativamente a los inmigrantes indocumentados y de otra forma sería inaceptable si se aplicaran a los ciudadanos o residentes con una condición migratoria lícita ${ }^{3}$. Sin embargo, en las palabras del Juez Stevens de la Corte Suprema, "hasta uno cuya presencia en este país sea ilegal, involuntaria o transitoria goza de (cierta) protección constitucional" ${ }^{4}$.

La Cuarta Enmienda protege en contra de registros e incautaciones irrazonables asumiendo que la misma es aplicable ${ }^{5}$. Los ciudadanos y residentes legales de los Estados Unidos son titulares de las garantías constitucionales, como lo es la Cuarta Enmienda $^{6}$. La respuesta para los inmigrantes indocumentados no es tan clara ${ }^{7}$. En cambio, cuando le ha tocado a la Corte Suprema determinar si la Cuarta Enmienda es aplicable a los inmigrantes indocumentados ha respondido con el proverbio "depende". Los inmigrantes indocumentados en los Estados Unidos están viviendo en el limbo de la Cuarta Enmienda.

La incertidumbre en cuanto a la Cuarta Enmienda y los inmigrantes indocumentados resulta en un efecto escalofriante ${ }^{8}$. Las libertades constitucionales son delicadas y requieren un "breathing space" para sobrevivir9. Las libertades constitucionales sufren cuando el Estado regula excesivamente porque la "amenaza de sanciones puede disuadir su ejercicio casi efectivamente igual que la aplicación misma de sanciones"10. Cualesquiera sean las libertades constitucionales que tengan los inmigrantes indocumentados, estas son relajadas por la incertidumbre en cuanto a sus derechos y un miedo hacia las sanciones

1 http://www. nps.gov/stli/learn/historyculture/colossus.htm, National Park Service. Consulta realizada el día 08 de diciembre de 2018.

2 FANDL, Kevin J. Immigration Posses: U.S. Immigration Law and Local Enforcement Practices. En Journal of Legislation, vol. 34, núm. 1, 2008, pp. 16-37.

3 Mathews v. Diaz, 426 U.S. 67, 79-80 (1976).

4 Ídem. at 77.

5 U.S. CONST. amend. IV.

6 WATKINS, Henry G. The Fourth Amendment and the Ins: An Update on Locating the Undocumented and a Discussion on Judicial Avoidance of Race-Based Investigative Targeting in Constitutional Analysis, En San Diego Law Review, vol. 28, núm. 3, 1991, pp. 499-592.

7 Ídem.

8 See generally Note, The Chilling Effect in Constitutional Law, 69 COLUM. L. REV. 808 (1969).

9 Nat'1 Ass'n for Advancement of Colored People v. Button, 371 U.S. 415, 432-33 (1963).

10 Ídem. 
estatales ${ }^{11}$. Los inmigrantes indocumentados preferirían sufrir registros irrazonables que provocar a los agentes estatales invocando los derechos de la Cuarta Enmienda que podrían o no tener ${ }^{12}$. La incertidumbre que rodea a la Cuarta Enmienda entonces convierte las libertades constitucionales, que los Padres Fundadores pretendían sea un escudo de protección, en una espada que el Estado puede utilizar en contra de una población vulnerable.

El Departamento de Seguridad Nacional ("DHS", por sus siglas en inglés) está actualmente probando los límites de la protección que brinda la Cuarta Enmienda con su Alternativa a los Programas de Detención ${ }^{13}$. El DHS no cuenta con suficientes centros de detención para albergar a todos los inmigrantes indocumentados que vienen a los Estados Unidos ${ }^{14}$. Adicionalmente, los centros de detención son costosos, entre $\$ 130$ y $\$ 330$ por persona y por día dependiendo del centro de detención ${ }^{15}$. Como resultado, el DHS está experimentando con programas de bajo costo para monitorear a los inmigrantes indocumentados ${ }^{16}$, el más reciente es el programa RGV 25017. Bajo este tipo de programa, el DHS pone en libertad a las familias inmigrantes indocumentadas pero requiere que los jefes de dichas familias utilicen un brazalete con GPS en el tobillo por una cantidad de tiempo indeterminada ${ }^{18}$. Esta alternativa del brazalete en el tobillo solo tiene un costo promedio de $\$ 5$ por día ${ }^{19}$.

Los inmigrantes indocumentados usualmente se refieren a estos brazaletes de tobillo como grilletes ${ }^{20}$. Una de las razones por las que los brazaletes de tobillo recuerdan a los grilletes es porque los dispositivos tienen cuerdas cortas y deben ser cargados frecuentemente por un tiempo estimado de dos horas cada vez ${ }^{21}$. Esto hace encontrar un trabajo, y más aún mantener uno, una tarea difícil, si no, imposible ${ }^{22}$. Los inmigrantes indocumentados se quejan también de que los

11 https://www.hrw.org/news/2014/05/14/us-immigrants-afraid-call-911, Human Rights Watch.

Consulta realizada el día 09 de diciembre de 2018.

12 Ídem.

13 CALDWELL, Alicia A. DHS Is Using GPS-Enabled Ankle Bracelets To Track Immigrant Families Crossing The Border. MCGILL, 2014. http:/ /oppenheimer.mcgill.ca/DHS-Is-Using-GPS-EnabledAnkle?lang=fr.

14 Ídem.

15 http:/www.latimes.com/nation/immigration/la-na-immigrant-ankle-monitors-20150802story.html, Los Angeles Times.

Consulta realizada el día 09 de diciembre de 2018.

16 CALDWELL, Alicia A. DHS Is Using GPS-Enabled Ankle Bracelets To Track Immigrant Families Crossing The Border. MCGILL, 2014. http:/ / oppenheimer.mcgill.ca/DHS-Is-Using-GPS-EnabledAnkle?lang=fr.

17 Ídem.

18 Ídem.

19 http:/www.latimes.com/nation/immigration/la-na-immigrant-ankle-monitors-20150802story.html, Los Angeles Times. Consulta realizada el día 09 de diciembre de 2018.

20 Ídem.

21 Ídem.

22 Ídem. 
brazaletes de tobillo producen calor e irritan su piel23. Más notablemente, los brazaletes de tobillos son un visible estigma que etiqueta a los inmigrantes indocumentados como criminales ${ }^{24}$. Esto afecta la habilidad de los inmigrantes indocumentados para encontrar un trabajo y acceder a una vivienda ${ }^{25}$. Al margen de los potenciales problemas de consentimiento legal y el debilitador estigma criminal vinculado con llevar puestos los brazaletes de tobillo, el DHS monitoreó un total de 23,000 inmigrantes indocumentados con brazaletes de tobillo en 2015, y planea incrementar este número a 53,000 en 201626.

La Corte Suprema se refirió a los peligros que las tecnologías avanzadas, como los brazaletes de tobillo, representan frente a los derechos de la Cuarta Enmienda de un individuo en múltiples casos. Hasta la Corte Suprema ha señalado en diversas instancias que la utilización de dispositivos GPS para realizar registros constituye una violación de la Cuarta Enmienda27. En United States v. Jones, la Corte Suprema señaló que el seguimiento de un automóvil por GPS era un registro irrazonable bajo la Cuarta Enmienda. Más recientemente, la Corte Suprema dio un paso más en el establecimiento de un precedente en contra del uso estatal de la tecnología GPS para registros. En Grady v. North Carolina, la Corte Suprema dijo que un programa civil que utilizaba brazaletes de tobillo con GPS para monitorear ofensores sexuales reincidentes era una violación de la Cuarta Enmienda y constituía un registro 28 .

La Corte Suprema ha demostrado un gran respeto hacia la privacidad y una fuerte desaprobación de los registros estatales irrazonables del cuerpo de una persona o sus efectos en Jones y Grady ${ }^{29}$. Jones y Grady son hitos de la Cuarta Enmienda, pero sigue siendo ambiguo cómo el estatus legal de una persona en el país podría influenciar el análisis de la Cuarta Enmienda, ya que este no fue materia de ninguno de estos casos.

La Corte Suprema se ha referido a los derechos constitucionales de los inmigrantes indocumentados en diversos casos, pero sigue siendo incierto cuáles son los derechos constitucionales sobre los cuáles los inmigrantes indocumentados son titulares o cuándo pueden invocar estos derechos constitucionales. En Immigration and Naturalization Service v. López-Mendoza, la mayoría de los jueces simplemente asumió que los inmigrantes indocumentados se benefician de los derechos de la Cuarta Enmienda ${ }^{30}$. La Corte Suprema en López-Mendoza resaltó la importancia de los derechos de la Cuarta Enmienda para todas las personas, pero no hizo la

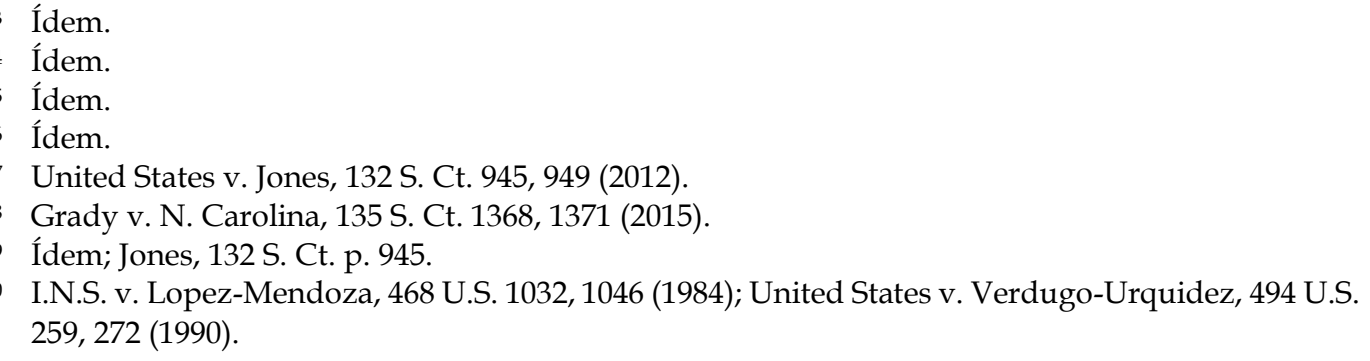


distinción ni definió la palabra "persona ${ }^{31 . " ~ L a ~ C o r t e ~ S u p r e m a, ~ e n ~ U n i t e d ~ S t a t e s ~ v . ~}$ Verdugo-Urquidez, limitó el alcance de los derechos de la Cuarta Enmienda por medio del debate del significado de la palabra "persons" versus la palabra "people32." No obstante, al margen de un extenso análisis constitucional, los jueces de la Corte Suprema en Verdugo-Urquidez no pudieron llegar a una decisión definitiva sobre los derechos de la Cuarta Enmienda de los inmigrantes indocumentados ${ }^{33}$. Los jueces, sin embargo, sí proporcionaron una mayor claridad sobre el tema al crear un examen sustancial de conexiones ${ }^{34}$.

Este artículo explorará cómo el estatus de los inmigrantes indocumentados en los Estados Unidos puede influenciar la determinación de una corte de si la Cuarta Enmienda se encuentra implicada en los programas del DHS que requieren un monitoreo basado en brazaletes de tobillo. Este artículo está compuesto por tres partes. La Parte I discute la posibilidad de que los inmigrantes indocumentados se beneficien de los derechos de la Cuarta Enmienda. La Parte II examina el uso de dispositivos GPS y la constitucionalidad de los programas del DHS como el RGV 250. La parte III concluye que los programas del DHS que utilizan los brazaletes de tobillos son inconstitucionales.

\section{Inmigración ilegal en los Estados Unidos}

\section{i. El DHS en un contexto histórico}

Estados Unidos ha estado preocupado por el problema de la inmigración desde el final de la década de los 70s 35 . Durante este tiempo, el Congreso empezó a adoptar medidas preventivas en contra de la posibilidad del ingreso de inmigrantes porque Estados Unidos temía una guerra fría con Francia ${ }^{36}$. El Congreso propuso diversos proyectos de ley que fueron eventualmente firmados por el presidente John Adams $^{37}$. Estos proyectos de ley resultaron en los Alien and Sedition Acts of 179838, los cuales entregaron a los agentes federales el poder y la discreción para sacar a todos los inmigrantes peligrosos ${ }^{39}$. Como resultado de este amplio poder, cualquier discrepancia política era criminalizada efectivamente ${ }^{40}$.

La inmigración fue radicalmente reformada de nuevo en 1933 cuando el presidente Franklin D. Roosevelt emitió la Executive Order 6166 y creó la Immigration and

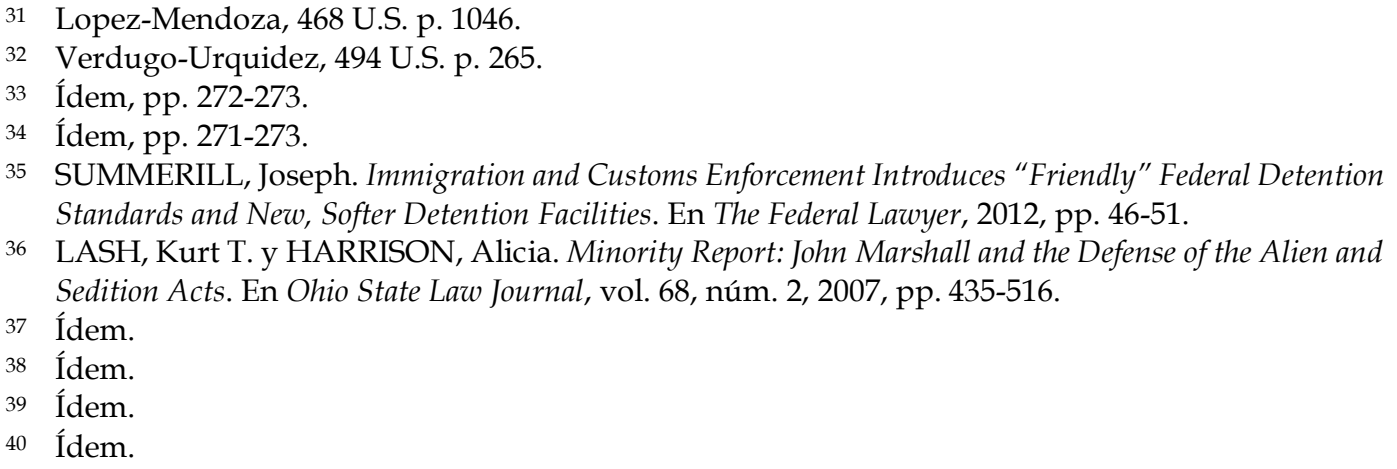


Naturalization Service ("INS")41. Después de la Executive Order, la agencia del INS fue encargada de las funciones de inmigración y deportación que inicialmente se encontraban a cargo del Bureau of Immigration y el Bureau of Naturalization ${ }^{42}$.

El INS fue la primera agencia que hizo frente a los problemas de inmigración hasta que el presidente George W. Bush reevaluó las políticas de inmigración después de los ataques terroristas del 11 de septiembre. ${ }^{43}$ El presidente Bush firmó el Homeland Security Act el 25 de noviembre de 2002, que eliminó el INS y creó el DHS44. Bajo el Homeland Security Act, el DHS tiene amplia jurisdicción de modo que puede: “(A) prevent terrorist attacks within the United States; (B) reduce the vulnerability of the United States to terrorism; [and] (C) minimize the damage, and assist in the recovery, from terrorist attacks that do occur within the United States $45 . "$

Bajo el reciente DHS, los deberes formales del INS fueron transferidos al Immigration and Customs Enforcement ("ICE")46. La misión del ICE es localizar inmigrantes indocumentados, dinero y material que podría estar ligado a terrorismo o a actividades criminales en general ${ }^{47}$. El ICE promueve y hace cumplir la misión del DHS por medio de arrestos, detenciones, redadas, y más recientemente, el uso de brazaletes de tobillo para el monitoreo ${ }^{48}$.

La historia de la inmigración en los Estados Unidos revela que "por razones reconocidas desde hace mucho tiempo como válidas, la responsabilidad de regular la relación entre los Estados Unidos y nuestros visitantes extranjeros se ha comprometido con las ramas políticas del Gobierno Federal ${ }^{49}$." Como resultado, desde la década de los 70s, la regulación de la inmigración, especialmente en tiempos de guerra o disturbios políticos, ha empujado los límites constitucionales ${ }^{50}$. A pesar de la discreción de los poderes ejecutivo y legislativo sobre la inmigración, la Corte Suprema ha señalado que el DHS todavía está

41 SUMMERILL, Joseph. Immigration and Customs Enforcement Introduces "Friendly" Federal Detention Standards and New, Softer Detention Facilities. En The Federal Lawyer, 2012, p. 46.

42 Ídem.

43 THESSIN, Jonathan. Department of Homeland Security, 40 HARV. J. ON LEGIS. 513, 2003.

44 Ídem.

45 Homeland Security Act of $2002 \S 101$.

46 SUMMERILL, Joseph. Immigration and Customs Enforcement Introduces "Friendly" Federal Detention Standards and New, Softer Detention Facilities. En The Federal Lawyer, 2012, p. 46.

47 Ídem.

48 FANDL, Kevin J. Immigration Posses: U.S. Immigration Law and Local Enforcement Practices. En Journal of Legislation, vol. 34, núm. 1, 2008, p. 23 y CALDWELL, Alicia A. DHS Is Using GPSEnabled Ankle Bracelets To Track Immigrant Families Crossing The Border. MCGILL, 2014. http:/ /oppenheimer.mcgill.ca/DHS-Is-Using-GPS-Enabled-Ankle?lang=fr..

49 Traducción libre de: "for reasons long recognized as valid, the responsibility for regulating the relationship between the United States and our alien visitors has been committed to the political branches of the Federal Government." Mathews, 426 U.S. p. 8.

50 LASH, Kurt T. y HARRISON, Alicia. Minority Report: John Marshall and the Defense of the Alien and Sedition Acts. En Ohio State Law Journal, vol. 68, núm. 2, 2007. Y, THESSIN, Jonathan. Department of Homeland Security, 40 HARV. J. ON LEGIS. 513, 2003. 
"subject to important constitutional limitations $51 . "$ La amplia misión del DHS no justifica sus métodos de coacción posiblemente inconstitucionales ${ }^{52}$. El DHS debe de actuar solamente por medio de "constitutionally permissible means ${ }^{53}$."

\section{ii. El problema: ¿qué derechos tienen los inmigrantes indocumentados?}

La inmigración se encuentra bajo el control de la ley federal, pero el gobierno federal y las cortes no han sido exitosos en proveer guías claras ${ }^{54}$. Con respecto a la inmigración, hay muchos vacíos en la ley porque no existe una reforma integral de la inmigración a nivel federal ${ }^{55}$. Por ejemplo, en noviembre de 2007, 46 estados adoptaron una legislación relacionada a la inmigración y más de 1,562 proyectos de ley fueron introducidos en los 50 estados $^{56}$. En total, fue un incremento de casi $300 \%$ desde el año $2006^{57}$. Estos vacíos crean inconsistencias en el Derecho y dotan al DHS y a los oficiales de inmigración con una excesiva discreción ${ }^{58}$.

La inmigración es en su núcleo una materia compleja que es complicada más allá por discrepancias políticas en relación a cuál es la mejor manera para manejar a los inmigrantes sin descuidar la seguridad nacional ${ }^{59}$. Las cortes federales intervienen cuando los oficiales de inmigración o las agencias sobrepasan los límites constitucionales, pero ni siquiera la Corte Suprema ha previsto mucha guía en cuanto a la inmigración ${ }^{60}$. La falta de claridad en relación con los derechos constitucionales de los inmigrantes indocumentados es en gran parte porque la Constitución no distingue entre inmigrantes documentados e indocumentados en cuanto a las garantías constitucionales ${ }^{61}$. Las cortes entonces se encuentran divididas y solo han podido acordar que los inmigrantes indocumentados gozan, en alguna medida, de la protección de la Cuarta Enmienda ${ }^{62}$.

51 Zadvydas v. Davis, 533 U.S. 678, 695 (2001). PAPST, Kelsey E. “Protecting the Voiceless: Ensuring Ice's Compliance with Standards That Protect Immigration Detainees". En McGeorge Law Review, vol. 40, núm. 1, 2009, pp. 261-289.

52 PAPST, Kelsey E. "Protecting the Voiceless: Ensuring Ice's Compliance with Standards That Protect Immigration Detainees". En McGeorge Law Review, vol. 40, núm. 1, 2009, p. 265.

53 Ídem. (citando a INS v. Chadha, 462 U.S. 919, 941-42 (1983)).

54 FANDL, Kevin J. Immigration Posses: U.S. Immigration Law and Local Enforcement Practices. En Journal of Legislation, vol. 34, núm. 1, 2008, pp. 20, 22.

55 Ídem.

56 Ídem.

57 Ídem.

58 Ídem.

59 FANDL, Kevin J. Immigration Posses: U.S. Immigration Law and Local Enforcement Practices. En Journal of Legislation, vol. 34, núm. 1, 2008, p. 23.

60 ANTOS-FALLON, Marisa. The Fourth Amendment and Immigration Enforcement in the Home: Can Ice Target the Utmost Sphere of Privacy? En Fordham Urban Law Journal, vol. 35, núm. 5, 2008, pp. 999-1032.

61 FANDL, Kevin J. Immigration Posses: U.S. Immigration Law and Local Enforcement Practices. En Journal of Legislation, vol. 34, núm. 1, 2008, p. 29.

62 ANTOS-FALLON, Marisa. The Fourth Amendment and Immigration Enforcement in the Home: Can Ice Target the Utmost Sphere of Privacy? En Fordham Urban Law Journal, vol. 35, núm. 5, 2008, p. 1003. 


\section{La asunción de los derechos de la Cuarta Enmienda: Immigration and Naturalization Service v. López-Mendoza}

Adan López-Mendoza se encontraba trabajando en un tienda de transmisión en San Mateo, California en $1976^{63}$. Después de haber recibido una propina, los agentes del INS visitaron la tienda de transmisión para investigar ${ }^{64}$. Sin embargo, los agentes del INS llegaron sin una orden judicial para registrar el lugar ni para arrestar a alguna de las personas que se encontraban en las instalaciones ${ }^{65}$. El propietario de la tienda de transmisión se negó a que los agentes del INS entrevistaran a los trabajadores, pero uno de los agentes del INS logró hablar con López-Mendoza, mientras que otro agente del INS estaba teniendo una conversación con el propietario ${ }^{66}$.

El agente del INS le hizo múltiples preguntas a López-Mendoza y este reveló al último que nació en México y no tenía lazos familiares en los Estados Unidos ${ }^{67}$. En este punto, el agente del INS arrestó a López-Mendoza y lo llevó a una oficina del INS68. En esta oficina del INS, López-Mendoza reveló que nació en México, era un ciudadano mexicano, y que ingresó a los Estados Unidos ilegalmente sin una inspección ${ }^{69}$.

El INS empezó los procedimientos de deportación en contra de López-Mendoza, pero López-Mendoza cuestionó la legalidad de su arresto ${ }^{70}$. El caso de LópezMendoza atravesó el sistema judicial hasta que llegó a la Corte de Apelaciones ${ }^{71}$. La Corte de Apelaciones dejó sin efectos la orden de deportación y remitió el caso para determinar si los derechos de la Cuarta Enmienda de López-Mendoza habían sido violados durante su detención ${ }^{72}$. La Corte de Apelaciones mencionó los "derechos de la Cuarta Enmienda de López-Mendoza" pero no especificó ni analizó cuáles derechos de la Cuarta Enmienda tenía López-Mendoza bajo la Constitución ${ }^{73}$.

Cuando el caso de López-Mendoza llegó a la Corte Suprema, los jueces ya habían asumido que López-Mendoza tenía los derechos de la Cuarta Enmienda a pesar de que este era un inmigrante indocumentado ${ }^{74}$. La Corte Suprema se enfocó, por el contrario, en si López-Mendoza tenía o no el derecho de aplicar la regla de exclusión de la Cuarta Enmienda en procesos civiles ${ }^{75}$.

3 Lopez-Mendoza, 468 U.S. p. 1035.

64 Ídem.

65 Ídem.

66 Ídem.

67 Ídem.

68 Lopez-Mendoza, 468 U.S. p. 1035.

9 Ídem.

Ídem, pp. 1035-1036.

1 Ídem, p. 1036.

Ídem.

Lopez-Mendoza, 468 U.S. p. 1036

Verdugo-Urquidez, 494 U.S. p. 272.

Lopez-Mendoza, 468 U.S. p. 1034. 
López-Mendoza argumentó ante la Corte Suprema que la regla de exclusión era necesaria para salvaguardar sus derechos de la Cuarta Enmienda en los Estados Unidos $^{76}$. En este punto, hasta López-Mendoza estaba asumiendo que gozaba de los derechos de la Cuarta Enmienda77. Los jueces de la Corte Suprema no corrigieron la asunción López-Mendoza ni le pidieron que especifique cuáles de sus derechos de la Cuarta Enmienda se encontraba en peligro ${ }^{78}$.

La Corte Suprema en cambio dijo al último que la regla de exclusión no era aplicable en procesos civiles de deportación ${ }^{79}$. El juez O'Connor explicó en nombre de la mayoría que "tan importante como es proteger los derechos de la Cuarta Enmienda para todas [énfasis agregado] las personas, no hay algún indicador convincente que la aplicación de la regla de exclusión en procesos civiles de deportación contribuiría a ese finn ${ }^{80}$." En su opinión, el juez $\mathrm{O}^{\prime}$ Connor no distinguió entre los derechos de la Cuarta Enmienda de los inmigrantes indocumentados y de las personas con un estatus migratorio legal.

El caso López-Mendoza no señala expresamente que los inmigrantes indocumentados tienen alguno de los derechos de la Cuarta Enmienda ${ }^{81}$. Sin embargo, durante toda su opinión, la Corte Suprema supone que los inmigrantes indocumentados tienen como mínimo algunos derechos de la Cuarta Enmienda ${ }^{82}$.

\section{Limitando los alcances de la Cuarta Enmienda: United States v. Verdugo- Urquidez}

Los inmigrantes indocumentados se han basado en lo señalado en López-Mendoza para invocar los derechos de la Cuarta Enmienda, pero López-Mendoza no establece que los inmigrantes indocumentados tienen los derechos de la Cuarta Enmienda ${ }^{83}$. López-Mendoza limita los derechos de la Cuarta Enmienda de los inmigrantes indocumentados porque prohíbe el uso de la regla de exclusión durante procedimientos civiles de exclusión ${ }^{84}$. United States $v$. Verdugo-Urquidez clarifica lo dispuesto en López-Mendoza y detalla el contexto de la Cuarta Enmienda para inmigrantes indocumentados ${ }^{85}$.

Rene Martin Verdugo-Urquidez era un ciudadano mexicano que residía en México ${ }^{86}$. La Agencia Antidrogas (DEA) sospechaba que Verdugo-Urquidez estaba asociado con una organización que transportaba narcóticos ilegalmente a

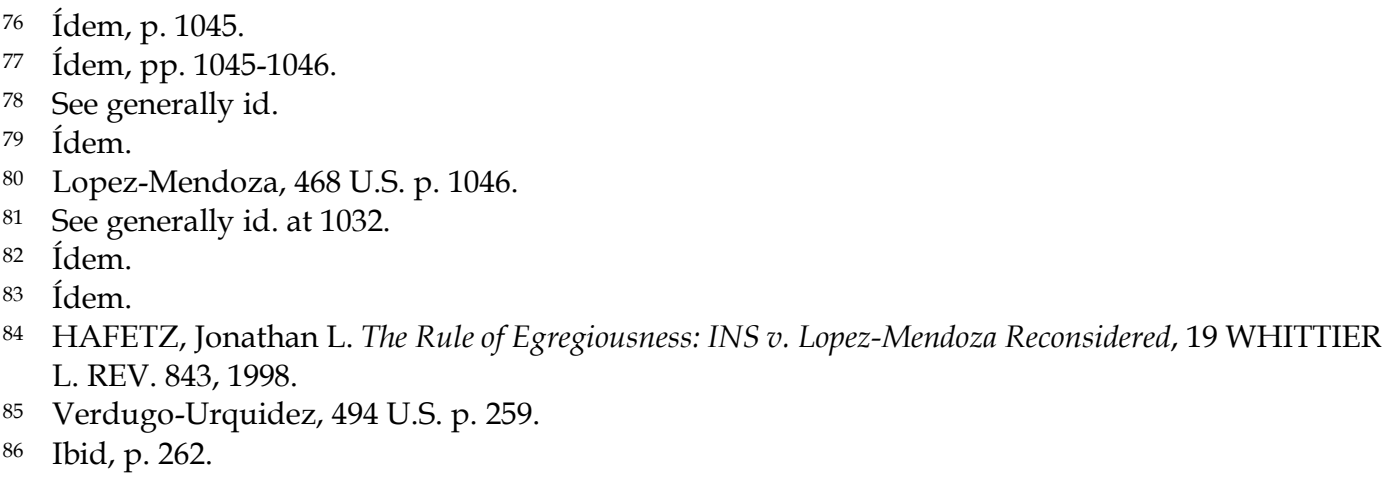


los Estados Unidos87. Verdugo-Urquidez también era sospechoso por la muerte y tortura de un agente de la DEA ${ }^{88}$. El gobierno de los Estados Unidos obtuvo una orden judicial para su arresto en 1985 y capturó a Verdugo-Urquidez en México en enero de 1986 con la ayuda de los oficiales mexicanos encargados de hacer cumplir la ley ${ }^{89}$. Después de su arresto, el gobierno de los Estados Unidos llevó a Verdugo-Urquidez a una estación de Patrulla Fronteriza en Calexico, California, donde fue arrestado por agentes de los Estados Unidos y fue posteriormente trasladado a un centro correccional en San Diego, California ${ }^{90}$.

Luego de que Verdugo-Urquidez fue arrestado y detenido en los Estados Unidos, un agente de la DEA ordenó el registro de las residencias mexicanas que había tenido Verdugo-Urquidez en Mexicali y San Felipe ${ }^{91}$. El agente de la DEA solicitó la autorización del Director General de la Policía Federal de México, pero nunca solicitó el consentimiento de Verdugo-Urquidez ni consiguió una orden judicial de un juez neutral e independiente ${ }^{92}$. Los oficiales mexicanos encargados de hacer cumplir la ley accedieron a ayudar a la DEA con los registros y por medio de un esfuerzo conjunto descubrieron evidencia incriminadora, como hojas de registro que reflejaban el contrabando de ciertas cantidades de marihuana, en su residencia de Mexicali93.

Verdugo-Urquidez solicitó la supresión de toda la evidencia recolectada en los registros en sus residencias mexicanas porque era una violación de sus derechos de la Cuarta Enmiendo pues la DEA no tenía una orden judicial ${ }^{94}$. La Corte del Distrito concedió su solicitud para suprimir y un panel dividido de la Corte de Apelaciones del Noveno Circuito la confirmó ${ }^{95}$. Cuando el caso de VerdugoUrquidez llegó a la Corte Suprema, la pregunta presentada era, "si la Cuarta Enmienda se aplica a la búsqueda y registro de los agentes de los Estados Unidos de la propiedad de un alien no residente en un país extranjero ${ }^{96 . "}$

La Corte Suprema inició resolviendo las disputas constitucionales de las cortes más bajas por medio de la distinción de la Cuarta Enmienda con la Quinta y Sexta Enmienda ${ }^{97}$. La Corte Suprema quiso aclarar solo porque Verdugo-Urquidez se benefició del derecho a un debido proceso bajo la Quinta Enmienda y un juicio justo bajo la Sexta Enmienda, no significaba que se podría beneficiar de la protección de la Cuarta Enmienda contra los registros arbitrarios ${ }^{98}$. La Quinta y Sexta Enmienda son derechos judiciales de los acusados criminales, pero la Cuarta

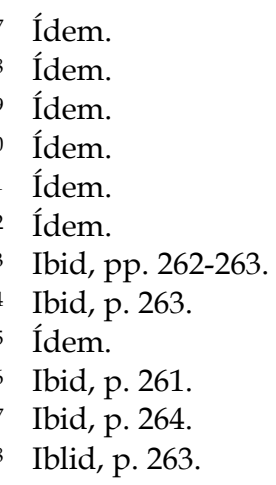


Enmienda podría ser aplicable sin tomar en cuenta si el juicio se lleva a cabo o si se introduce evidencia en el juicio ${ }^{99}$. Más aún, a diferencia de la Quinta y Sexta Enmienda, las violaciones de la Cuarta Enmienda son "fully accomplished" al momento de la intrusión arbitraria del gobierno100. En el caso de VerdugoUrquidez, esto significa que la posible violación de la Cuarta Enmienda se llevó a cabo en México, fuera de los Estados Unidos ${ }^{101 .}$

La Corte Suprema comienza su análisis con datos históricos para explicar que la Cuarta Enmienda no tenía la intención de otorgar una protección contra registros y búsquedas fuera de los Estados Unidos ${ }^{102}$. La investigación histórica revela que los autores de la Constitución no tenían en mente que los Estados Unidos tenía el poder de realizar registros y búsquedas fuera de sus fronteras ${ }^{103}$. Esto significaría que las garantías de la Cuarta Enmienda no se extenderían a Verdugo-Urquidez porque tenían como objetivo "protect the people of the United States against arbitrary action by their own Government" en asuntos domésticos ${ }^{104}$.

Al margen de la investigación histórica, Verdugo-Urquidez se basó en una serie de casos que sostenían que los extranjeros se benefician de ciertos derechos constitucionales para argumentar que la protección de la Cuarta Enmienda debía aplicarse al presente caso ${ }^{105}$. La Corte Suprema distinguió los casos previos con Verdugo-Urquidez al señalar que, a diferencia de Verdugo-Urquidez, esos extranjeros gozaban de las garantías constitucionales cuando ingresaban a los Estados Unidos porque se configuraban "conexiones sustanciales con este país ${ }^{106 . " ~}$ Por ejemplo, el inmigrante indocumentado en López-Mendoza "aceptó voluntaria y presumiblemente ciertas obligaciones sociales107." Por otro lado, los agentes de la DEA llevaron a Verdugo-Urquidez a la fuerza a los Estados Unidos y una "presencia lícita pero involuntaria" no era suficiente para desarrollar cualquier conexión sustancial con el país ${ }^{108}$.

Al final, la Corte Suprema no se convenció por los argumentos de VerdugoUrquidez y sostuvo que la Cuarta Enmienda no se aplicaba al caso particular ${ }^{109}$. Aunque la Corte Suprema dio un mejor entendimiento de la Cuarta Enmienda y creó un examen sustancial de conexión, todavía no respondió si la Cuarta Enmienda protege a los inmigrantes indocumentados ${ }^{110}$.

\footnotetext{
99 Íbid, p. 264.

100 Ídem.

101 Ídem.

102 Ibid, p. 266.

103 Ídem.

104 Ídem.

105 Ibid pp. 270-271.

106 Ibid, p. 271.

107 Ibid, p. 273.

108 Ibid, pp. 262-271.

109 Ibid, pp. 274-275.

110 Ibid. p. 286.
} 


\section{El panorama de la Cuarta Enmienda}

\section{i. Introduciendo la tecnología a la Cuarta Enmienda}

La Cuarta Enmienda establece que las personas tienen el derecho a "estar seguro en sus personas, casas, documentos y efectos en contra de registros y búsquedas irrazonables111." La Cuarta Enmienda ha sido reiteradamente un tema de discusión en las cortes porque los avances tecnológicos proveen a los agentes encargados de hacer cumplir la ley con herramientas para llevar a cabo búsquedas agresivas y prolongadas ${ }^{112}$. Esta conducta de los agentes encargados de hacer cumplir la ley ha inspirado a diversos jueces a realizar "referencias judiciales a distopía y el 1984 de George Orwell" porque se siente como si el "hermano mayor" estuviese siempre mirando ${ }^{113}$.

Con el paso de los años, los agentes encargados de hacer cumplir la ley se han basado en la tecnología, como localizadores, para rastrear sospechosos ${ }^{114}$. Sin embargo, el avance tecnológico más reciente utilizado por los agentes encargados de hacer cumplir la ley es un sistema de posicionamiento global ("GPS," por sus siglas en inglés) ${ }^{115}$. El GPS es uno de los métodos de rastreo preferidos por los agentes encargados de hacer cumplir la ley porque puede "obtener resultados que la vigilancia física nunca podría ${ }^{116 . "}$

El GPS es único de tres formas ${ }^{117}$. Primero, el rastreo por medio del GPS permite una vigilancia casi continua ${ }^{118}$. Por ejemplo, un dispositivo GPS puede emitir señales regularmente a una constelación de veintisiete satélites, que en teoría significa que los agentes encargados de hacer cumplir la ley podrían tener una vigilancia constante ${ }^{119}$. Segundo, un GPS no requiere mucha supervisión humana ${ }^{120}$. Por ejemplo, un solo policía podría vigilar múltiples sospechosos que están siendo rastreados al mismo tiempo ${ }^{121}$. Tercero, un GPS puede acceder a la información histórica y retroceder en el tiempo para revisar lugares y fechas de

111 U.S. CONST. amend. IV.

112 ARCILA, Fabio. GPS Tracking Out of Fourth Amendment Dead Ends: United States v. Jones and the Katz Conundrum. En North Carolina Law Review, vol. 91, núm. 1, 2012, pp. 1-78.

113 Ídem.

114 MILLER, Jordan. "New Age Tracking Technologies in the Post-United States v. Jones Environment: The Need for Model Legislation". En Creighton Law Review, vol. 48, núm. 3, 2015, pp. 553, 603.

115 ARCILA, Fabio. GPS Tracking Out of Fourth Amendment Dead Ends: United States v. Jones and the Katz Conundrum. En North Carolina Law Review, vol. 91, núm. 1, 2012, p. 3.

116 Ibid p. 54

117 Ídem.

118 Ídem.

119 MILLER, Jordan. "New Age Tracking Technologies in the Post-United States v. Jones Environment: The Need for Model Legislation". En Creighton Law Review, vol. 48, núm. 3, 2015, p. 561.

120 ARCILA, Fabio. GPS Tracking Out of Fourth Amendment Dead Ends: United States v. Jones and the Katz Conundrum. En North Carolina Law Review, vol. 91, núm. 1, 2012, p. 54.

121 MILLER, Jordan. "New Age Tracking Technologies in the Post-United States v. Jones Environment: The Need for Model Legislation". En Creighton Law Review, vol. 48, núm. 3, 2015, p. 562 . 
una forma que la vigilancia física de un policía no podría ${ }^{122}$. Por ejemplo, los agentes encargados de hacer cumplir la ley pueden acceder a la información de dispositivos GPS preexistentes, como el que ha sido instalado en el teléfono celular del sospechoso'123.

A diferencia de las tecnologías del pasado, un equipo GPS casi no tiene limitaciones tecnológicas ${ }^{124}$. Desde la perspectiva de un agente encargado de hacer cumplir la ley, esto hace la vigilancia más simple; pero desde la perspectiva de la Cuarta Enmienda, puede resultar en más búsquedas irrazonables. La vigilancia por medio del GPS puede ser intrusivo y revelar detalles íntimos a agentes encargados de hacer cumplir la ley que por medios de una vigilancia más tradicional no se enteraría. Por ejemplo, cuando un GPS manda una señal a múltiples satélites, entonces esos otros satélites pueden triangular adecuadamente la ubicación del GPS a pocos pies, o en algunos casos, a diez pulgadas. Hasta que las cortes lleguen a una decisión clara y consistente en relación con la legalidad de la tecnología de GPS en las búsquedas, las protecciones de la Cuarta Enmienda deben ser aplicadas con cuidado para evitar las búsquedas irrazonables ${ }^{125}$.

\section{ii. La evolución de la Cuarta Enmienda: Katz v. United States}

Tradicionalmente, las cortes usaban un análisis invasivo del common law para determinar si el Gobierno efectuó una búsqueda irrazonable bajo la Cuarta Enmienda ${ }^{126}$. Esto es comúnmente conocido como el modelo de propiedad de la Cuarta Enmienda127. Bajo este modelo, las cortes basarían sus análisis en si la búsqueda tuvo lugar en un "área protegida constitucionalmente ${ }^{128}$." No obstante, los avances en la tecnología han forzado a las cortes a adaptarse a ellos y considerar nuevos métodos para analizar la Cuarta Enmienda. Uno de los primeros casos en remodelar el análisis tradicional de la Cuarta Enmienda fue Katz v. United States ${ }^{129}$.

La parte demandante en Katz fue condenada bajo ocho acusaciones en la Corte del Distrito del Sur de California por transmitir información sobre apuestas desde Los Ángeles hacia Boston y Miami por teléfono ${ }^{130}$. Desconociendo esto, Katz fue grabado por la Oficina Federal de Investigación ("FBI") con un dispositivo electrónico para escuchar y grabar, en el momento en que estaba realizando las

\footnotetext{
122 ARCILA, Fabio. GPS Tracking Out of Fourth Amendment Dead Ends: United States v. Jones and the Katz Conundrum. En North Carolina Law Review, vol. 91, núm. 1, 2012, p. 54.

123 Ídem.

124 MILLER, Jordan. “New Age Tracking Technologies in the Post-United States v. Jones Environment: The Need for Model Legislation". En Creighton Law Review, vol. 48, núm. 3, 2015, p. 560.

125 KERR, Orin S. The Fourth Amendment and New Technologies: Constitutional Myths and the Case for Caution. En Michigan Law Review, vol. 102, núm. 5, 2004, pp. 801-888.

126 Jones, 132 S. Ct. p. 947.

127 ARCILA, Fabio. GPS Tracking Out of Fourth Amendment Dead Ends: United States v. Jones and the Katz Conundrum. En North Carolina Law Review, vol. 91, núm. 1, 2012, p. 5.

128 Katz v. United States, 389 U.S. pp. 347, 350 (1967).

129 Katz, 389 U.S. p. 347.

130 Ibid, p. 348.
} 
llamadas telefónicas y transmitiendo información de apuestas en una cabina telefónica pública131. En el juicio, al Gobierno se le permitió presentar evidencia de las llamadas telefónicas de Katz a pesar de las objeciones de este ${ }^{132}$. La Corte de Apelaciones rechazó que las grabaciones fueran una violación a la Cuarta Enmienda, toda vez que no se había efectuado acceso físico alguno a la cabina telefónica donde Katz se encontraba efectuando las llamadas. ${ }^{133}$ La Corte Suprema garantizó certiorari para responder las dos preguntas de la parte demandante: si la cabina telefónica pública era un área protegida constitucionalmente, la evidencia recopilada por un dispositivo electrónico resultaría una violación a la Cuarta Enmienda y si el acceso físico a un área protegida constitucionalmente es necesario para que se configure una violación a la Cuarta Enmienda134.

La Corte Suprema inició su análisis manifestando su desacuerdo con la formulación de problemas de Katz ${ }^{135}$. De acuerdo a la Corte Suprema, tanto Katz como el Gobierno están en desacierto al enfocar sus argumentos en si la cabina telefónica es un área protegida constitucionalmente ${ }^{136}$. Este tipo de argumentos se desvían del propósito fundamental de la Cuarta Enmienda, el cual es que "la Cuarta Enmienda protege a las personas, no a los lugares137." La Corte Suprema establece que la Cuarta Enmienda puede proteger constitucionalmente todo aquello que una persona busca o pretende mantener en privado ${ }^{138}$. Eso significa que la Cuarta Enmienda "no depende en la presencia o ausencia de acceso físico139." Es entonces en ese punto que la Corte Suprema empieza a dejar detrás el modelo invasivo del common law respecto a la Cuarta Enmienda hacia un modelo de privacidad ${ }^{140}$.

Bajo el modelo de privacidad, incluso si Katz hubiese ingresado a una cabina telefónica pública transparente, él aún esperaría evitar el "oído no invitado" de su conversación privada141. La Corte Suprema explicó que, "aquel que ocupe [una cabina telefónica], cierra la puerta detrás de él, y paga el costo que le permita realizar una llamada, está definitivamente facultado a asumir que las palabras que pronuncie en la boquilla o portavoz del teléfono no serán difundidas al mundo ${ }^{142 . "}$ La Corte Suprema revocó lo sostenido por la instancia inferior y concluyó que si Katz se hubiese encontrado en una oficina, un hogar o en una habitación de hotel, él estaba "facultado a saber que se mantendría libre de búsquedas e incautaciones

131 Ídem.

132 Ídem.

133 Ibid, pp. 348-349.

134 Katz, 389 U.S. pp. 349-350.

135 Ibid, p. 350.

136 Ídem.

137 Ídem, p. 351.

138 Ídem, p. 353.

139 Katz, 389 U.S. p. 353

140 ARCILA, Fabio. GPS Tracking Out of Fourth Amendment Dead Ends: United States v. Jones and the Katz Conundrum. En North Carolina Law Review, vol. 91, núm. 1, 2012, p. 5.

141 Katz, 389 U.S. p. 352.

142 Ídem. 
irrazonables", en especial cuando él claramente pretendía mantener sus conversaciones en privado ${ }^{143}$.

Katz destaca por su transición hacia un modelo de privacidad, pero también por la participación del Juez Harlan. Su participación coincide con la mayoría en que la Cuarta Enmienda "protege personas, no lugares," pero da un paso más en intentar responder lo que dicha protección garantiza a las personas ${ }^{144}$. El Juez Harlan intenta responder dicha interrogante creando una expectativa razonable del test de privacidad ${ }^{145}$. La expectativa razonable del test de privacidad es doble: (1) una persona tiene la expectativa subjetiva de privacidad y (2) dicha expectativa es aquella que la sociedad reconocería como razonable ${ }^{146}$. De acuerdo al Juez Harlan, la expectativa razonable del test de privacidad provee un mejor alcance de las protecciones de la Cuarta Enmienda ${ }^{147}$.

\section{iii. La Corte Suprema apunta directamente al GPS: United States v. Jones}

Lo que sostuvo la Corte Suprema en United States $v$. Jones es posiblemente una de las decisiones más importantes sobre la Cuarta Enmienda desde Katz ${ }^{148}$. Jones produjo múltiples opiniones, cada una con el potencial de alterar las prácticas de búsqueda e incautación de la Cuarta Enmienda149. Quizás el tema más importante, la Corte Suprema en Jones aclaró que a pesar de que había hecho transición hacia un modelo de privacidad en Katz, el más tradicional modelo invasivo del common law no había sido reemplazado ${ }^{150}$.

Antoine Jones era el propietario y operador de un club nocturno en D.C (Washington) cuando se volvió sospechoso de tráfico de narcóticos ${ }^{151}$. El FBI y la Policía Metropolitana investigaron y aplicaron una orden judicial ante la Corte Distrital del Distrito de Columbia para que se autorice el uso de GPS y así seguir los movimientos del carro registrado a nombre de la esposa de Jones ${ }^{152}$. La Corte emitió la orden judicial autorizando el uso del GPS, pero solo dentro del Distrito de Columbia y limitado a 10 días ${ }^{153}$. En el día 11, los agentes instalaron un equipo GPS en el carro mientras este se encontraba estacionado en un lote público en Maryland ${ }^{154}$. El Gobierno recopiló información del GPS por los siguientes 28 días

143 Ídem, p. 359.

144 Ídem, p. 361 (Harlan, J., concurring).

145 Ídem, p. 361.

146 Katz, 389 U.S. p. 361.

147 Ídem.

148 ARCILA, Fabio. GPS Tracking Out of Fourth Amendment Dead Ends: United States v. Jones and the Katz Conundrum. En North Carolina Law Review, vol. 91, núm. 1, 2012, p. 5.

149 Ídem.

150 IYENGAR, Vikram. United States $v$. Jones: Inadequate to Promote Privacy for Citizens and Efficiency for Law Enforcement. En Texas Journal on Civil Liberties \& Civil Rights, vol. 19, núm. 2, 2014, pp. 335347.

151 Jones, 132 S. Ct. p. 947.

152 Ídem.

153 Ídem.

154 Ídem. 
e incluso reemplazó las baterías del GPS cuando estas se agotaron ${ }^{155}$. El GPS retransmitió información detallada a los oficiales y reveló la locación del carro dentro de los 50 a 100 pies ${ }^{156}$. Para el final del período de vigilancia del GPS, el equipo retransmitió "2,000 páginas de datos durante el periodo de cuatro semanas ${ }^{157 . "}$

El Gobierno usó todos los datos del GPS para obtener múltiples cargos contra Jones y acusarlo de conspiración en la distribución de cocaína ${ }^{158}$. Jones fue sentenciado a cadena perpetua, pero la Corte de Apelaciones revocó dicha condena porque la evidencia del GPS fue recopilada sin orden judicial, lo cual era considerado violación de la Cuarta Enmienda. Tras denegar la petición del Gobierno para una nueva audiencia, la Corte Suprema garantizó certiorari ${ }^{159}$.

\section{Opinión mayoritaria: Juez Scalia}

La opinión mayoritaria, redactada por el Juez Scalia, retoma el más tradicional modelo invasivo del common law para analizar si había existido una violación a la Cuarta Enmienda en el caso Jones ${ }^{160}$. El Juez Scalia comienza explicando que hasta $K a t z$, la jurisprudencia sobre la Cuarta Enmienda estuvo basada en el modelo de delito de entrada y que este no podía ser soslayado únicamente debido a la creciente tendencia hacia el modelo de privacidad ${ }^{161}$. La Cuarta Enmienda enumera la privacidad en "personas, casas, papeles y efectos" porque tienen una conexión cercana a la propiedad ${ }^{162}$. Los derechos de la Cuarta Enmienda no surgen o se ven disminuidos solamente a partir de la expectativa razonable del test de privacidad ${ }^{163}$. Por el contrario, la Cuarta Enmienda solo dispondría "el derecho de las personas a estar seguras frente a búsquedas e incautaciones irrazonables ${ }^{164 . "}$ Asimismo, el Juez Scalia fundamentó que las cortes deberían depender del modelo de delito de entrada del common law incluso antes de cuestionar si una persona tuvo la expectativa razonable de privacidad ${ }^{165}$. Si sus afirmaciones sobre la importancia de la teoría del delito de entrada no fueran lo suficientemente claras, el Juez Scalia dispuso que "la expectativa razonable del test de privacidad en Katz ha sido añadido, y no sustituye, al test de delito de entrada del common-law166."

155 Ídem.

156 Ídem.

157 Ídem.

158 Ídem.

159 Ídem.

160 IYENGAR, Vikram. United States v. Jones: Inadequate to Promote Privacy for Citizens and Efficiency for Law Enforcement. En Texas Journal on Civil Liberties \& Civil Rights, vol. 19, núm. 2, 2014, p. 337.

161 Ídem.

162 Jones, 132 S. Ct. p. 949.

163 Ibid, p. 950.3

164 Ibid, p. 949.

165 IYENGAR, Vikram. United States v. Jones: Inadequate to Promote Privacy for Citizens and Efficiency for Law Enforcement. En Texas Journal on Civil Liberties \& Civil Rights, vol. 19, núm. 2, 2014,p. 337.

166 ARCILA, Fabio. GPS Tracking Out of Fourth Amendment Dead Ends: United States v. Jones and the Katz Conundrum. En North Carolina Law Review, vol. 91, núm. 1, 2012, p. 27; Jones, 132 S. Ct. P. 952. 
Después de trasladarse hacia el modelo de delito de entrada, el Juez Scalia estableció que las acciones del Gobierno constituyen una búsqueda acogida por la Cuarta Enmienda, toda vez que el Gobierno ocupó físicamente propiedad privada para obtener información cuando el dispositivo GPS se encontraba adherido al auto de Jones ${ }^{167}$. Según el Juez Scalia, dicha intrusión física en la propiedad de una persona "no deja duda" de que ocurrió una búsqueda dentro del alcance de la Cuarta Enmienda ${ }^{168}$. La Corte Suprema concluyó su análisis determinando que ocurrió una búsqueda, pero no analiza si esta fue razonable bajo lo establecido por la Cuarta Enmienda porque dicho tema específico no fue planteado en las instancias inferiores ${ }^{169}$.

\section{Acuerdo: Jueza Sotomayor}

La perspectiva del Juez Scalia sobre el modelo de delito de entrada del common law versus el modelo de privacidad son normas vinculantes mayoritarias debido a la quinta opinión de la Jueza Sotomayor ${ }^{170}$. La Jueza Sotomayor se sumó a los pronunciamientos del Juez Scalia sobre la advertencia de los peligros de la tecnología en su conformidad ${ }^{171}$. La Jueza Sotomayor estaba preocupada de que la tecnología haya avanzado tan pronto que fuera posible para el Gobierno monitorear personas sin la intrusión física en ningún espacio ${ }^{172}$.

La Jueza Sotomayor hizo referencia específicamente a los peligros del seguimiento por GPS debido a sus particulares atributos ${ }^{173}$. Ella observa que un equipo GPS revela información agregada, posee almacenamiento de data y capacidad de extracción, y es una herramienta fácilmente asequible174. Un GPS puede producir con exactitud "un registro preciso y comprensible de los movimientos en público de una persona que refleja con mucho detalle su círculo familiar, político, profesional, religioso y sexual ${ }^{175}$." Esto es un poder sin restricciones para recopilar información, que puede ser prestado al abuso fácilmente por parte de las autoridades de orden público ${ }^{176}$.

La conciencia del público de que los funcionarios encargados de hacer cumplir la ley podrían estar vigilando a los ciudadanos con GPS es también peligrosa, toda

\footnotetext{
167 Jones, 132 S. Ct. p. 949.

168 Ídem.

169 Ibid. 954.

170 ARCILA, Fabio. GPS Tracking Out of Fourth Amendment Dead Ends: United States v. Jones and the Katz Conundrum. En North Carolina Law Review, vol. 91, núm. 1, 2012, pp. 27-28.

171 IYENGAR, Vikram. United States v. Jones: Inadequate to Promote Privacy for Citizens and Efficiency for Law Enforcement. En Texas Journal on Civil Liberties \& Civil Rights, vol. 19, núm. 2, 2014,pp. 335336.

172 Jones, 132 S. Ct. p. 955 (Sotomayor, J., concurring).

173 Ídem.

174 ARCILA, Fabio. GPS Tracking Out of Fourth Amendment Dead Ends: United States v. Jones and the Katz Conundrum. En North Carolina Law Review, vol. 91, núm. 1, 2012, p. 20.

175 Jones, 132 S. Ct. p. 955 (Sotomayor, J., concurring).

176 Ibid, p. 956.
} 
vez que "frena las libertades asociativas y emocionales ${ }^{177}$." El conocimiento de que el monitoreo a través de GPS podría tomar lugar en cualquier momento podría "alterar la relación entre el ciudadano y el Gobierno de una manera que es hostil a sociedad democrática178." La Jueza Sotomayor concluyó su opinión concurrente solicitando que los futuros funcionarios y jueces consideren los atributos de un GPS al determinar lo que es una expectativa razonable de privacidad en una sociedad moderna ${ }^{179}$.

\section{iv. Seguimiento actual: Grady v. Carolina del Norte}

Torrey Dale Grady era un delincuente sexual reincidente que vivía en Carolina del Norte ${ }^{180}$. Grady fue declarado culpable de abuso sexual en segundo grado en 1997 y condenado nuevamente en el 2006 por tomarse libertades indecentes con un niño ${ }^{181}$. Después de cumplir su condena, Grady fue ordenado a comparecer ante el tribunal para determinar si debía someterse a supervisión satelital al ser un agresor sexual reincidente de acuerdo a las leyes de Carolina del Norte ${ }^{182}$.

El programa de monitorio basado en satélites fue esbozado en los Estatutos de Carolina del Norte183. Los Estatutos delimitan la logística del programa de monitoreo basado en satélites de acuerdo a lo siguiente,

“(c) El programa de monitoreo basado en satélites deberá usar un Sistema que provea lo siguiente:

(1) Seguimiento continuo y correlacionado en el tiempo de la localización geográfica del sujeto utilizando un sistema de posicionamiento global basado en la tecnología de localización de satélites y otras localizaciones.

(2) Notificación de las violaciones de los requisitos prescriptivos y proscriptores de horario o localización. La frecuencia de notificación puede variar de una vez al día (pasiva) a casi en tiempo real (activa) ${ }^{184 . "}$

En este caso, la supervisión basada en satélites exigiría que Grady llevara un dispositivo de rastreo en todo momento ${ }^{185}$. Grady argumentó que ser forzado a usar un dispositivo de rastreo constituiría una búsqueda poco razonable bajo la Cuarta Enmienda y que violaría sus derechos constitucionales.

El tribunal de primera instancia no estaba convencido por el argumento de Grady y le ordenó que se inscribiera en el programa de monitoreo basado en satélites "por

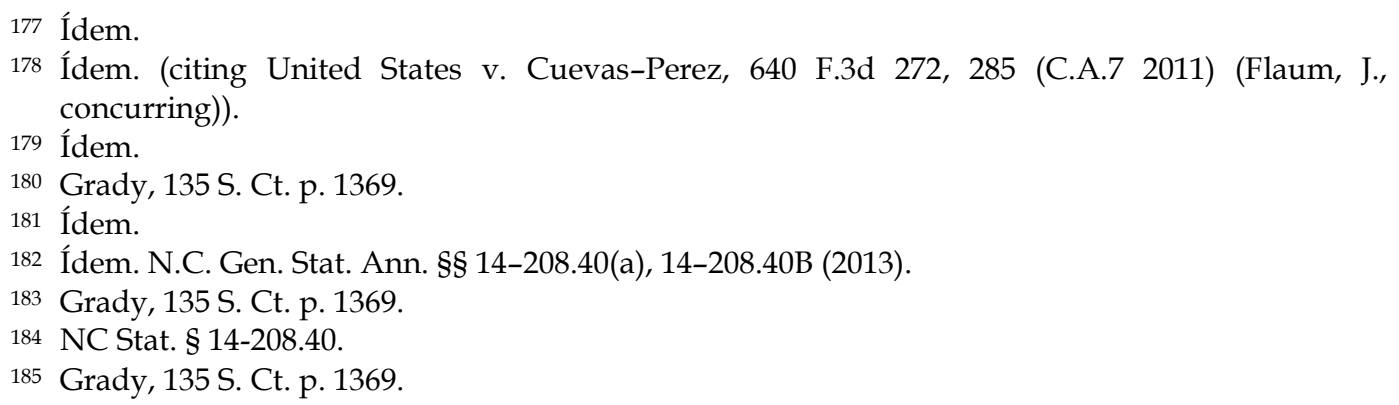


el resto de su vida186." Grady se basó en Jones para apelar su caso y propuso una pregunta sobre la Cuarta Enmienda187. La Corte de Apelaciones rechazó la impugnación de Grady por segunda vez, y Grady luego solicitó un examen discrecional con la Corte Suprema de Carolina del Norte, pero su apelación fue desestimada ${ }^{188}$. La Corte Suprema de los Estados Unidos finalmente emitió una opinión per curiam para tratar el caso de Grady.

La Corte Suprema inició su análisis citando casos previos que discutieron las violaciones de la Cuarta Enmienda que también ocurrieron porque el Gobierno "ocupó físicamente la propiedad privada con el propósito de obtener información ${ }^{189}$." La Corte Suprema declaró que si existe una intromisión física en un área constitucionalmente protegida, entonces no es necesario analizar si una persona tenía una expectativa razonable de privacidad190. La Corte Suprema también enfatizó que una búsqueda bajo la Cuarta Enmienda es posible aunque un programa de monitoreo sea de naturaleza civil porque "está bien establecido que la protección de la Cuarta Enmienda se extiende más allá de la esfera de las investigaciones criminales ${ }^{191}$."

En el caso de Grady, el programa de monitoreo basado en satélites desencadena la Cuarta Enmienda, porque el programa está diseñado para obtener información mediante intrusiones físicas en la persona de Grady ${ }^{192}$. Esta intrusión física resulta en una búsqueda de la Cuarta Enmienda0.193 La pregunta más importante para determinar la constitucionalidad del programa es si la búsqueda fue razonable ${ }^{194}$. La Corte Suprema remitió el caso a los tribunales de Carolina del Norte para determinar la razonabilidad de la búsqueda ${ }^{195}$. El Tribunal Supremo proporcionó a las cortes de Carolina del Norte una guía para analizar la razonabilidad de la búsqueda escribiendo que esta se determina analizando la totalidad de las circunstancias ${ }^{196}$. Para aplicar el test de la totalidad de las circunstancias, el Tribunal de Carolina del Norte tendría que mirar la naturaleza y el propósito de la búsqueda, así como la medida en que la búsqueda se entromete en las expectativas razonables de la privacidad ${ }^{197}$.

\section{Armando juntos el rompecabezas de la Cuarta Enmienda}

Los tribunales de López-Mendoza y Verdugo-Urquidez no declararon que los inmigrantes indocumentados no tienen derechos de la Cuarta Enmienda, pero

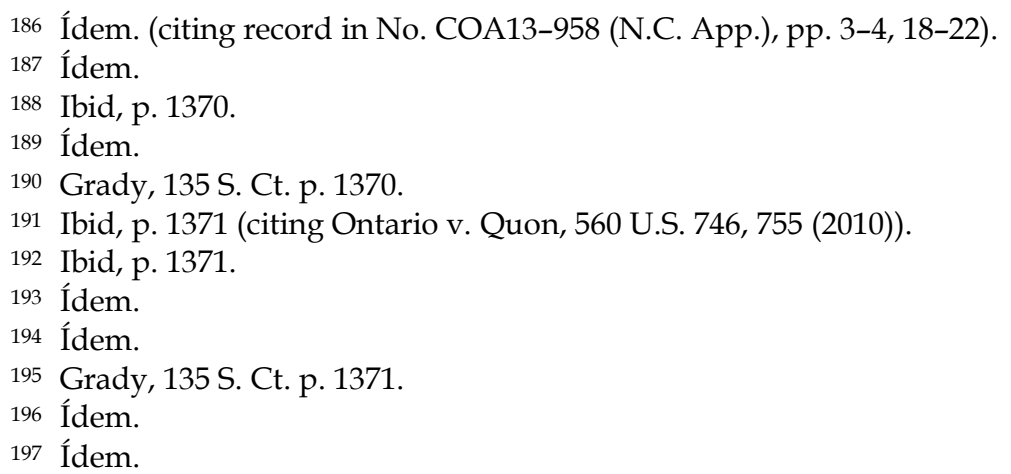


tampoco declararon que los inmigrantes indocumentados tienen derechos de la Cuarta Enmienda198. Simplemente no hay una respuesta clara sobre si los inmigrantes indocumentados tienen derechos de la Cuarta Enmienda o lo que incluyen esos derechos de la Cuarta Enmienda ${ }^{199}$. Sin embargo, López-Mendoza y Verdugo-Urquidez proporcionan una orientación sobre cómo un tribunal debe hacer un análisis de la Cuarta Enmienda200.

El primer factor a considerar en un análisis de la Cuarta Enmienda es si hay conexiones sustanciales con los Estados Unidos ${ }^{201}$. Según la Corte Suprema en Verdugo-Urquidez, un inmigrante indocumentado debe formar una conexión sustancial con los Estados Unidos antes de invocar las protecciones de la Cuarta Enmienda ${ }^{202}$. Aunque la Corte Suprema no detalló lo que constituye una conexión sustancial, indicó que la conexión debería ser voluntaria ${ }^{203}$.

El Juez Brennan y el Juez Marshall amplían el test de conexión sustancial en su disidencia para Verdugo-Urquidez204. Según el Juez Brennan y el Juez Marshall, Verdugo-Urquidez formó una conexión sustancial con los Estados Unidos porque estaba sujeto a sus leyes penales y estaba siendo investigado por violación de esas leyes ${ }^{205}$. Verdugo-Urquidez se enfrentaba a sanciones penales y posiblemente a prisión; por lo que "el Gobierno le ha hecho parte de nuestra comunidad para los propósitos de la Cuarta Enmienda206." El Gobierno, por lo tanto, puede, y lo hizo, proporcionar la conexión sustancial necesaria para justificar la invocación de las protecciones de la Cuarta Enmienda207.

El segundo factor a considerar en un análisis de la Cuarta Enmienda es dónde ocurrió la posible violación de la Cuarta Enmienda ${ }^{208}$. En López-Mendoza, la violación de la Cuarta Enmienda ocurrió en California, que está dentro de las fronteras de los Estados Unidos ${ }^{209}$. La Corte Suprema de López-Mendoza asumió que la Cuarta Enmienda era aplicable y no analizó la ubicación de la posible violación de la Cuarta Enmienda ${ }^{210}$. A diferencia de López-Mendoza, la posible violación de la Cuarta Enmienda en Verdugo-Urquidez tuvo lugar fuera de las fronteras de Estados Unidos en México ${ }^{211}$. La Corte Suprema en Verdugo-Urquidez declaró que la Cuarta Enmienda no tenía por objeto restringir la acción del

\footnotetext{
198 Ver Lopez-Mendoza, 468 U.S.1032; ver también Verdugo-Urquidez, 494 U.S. 259.

199 WATKINS, Henry G. The Fourth Amendment and the Ins: An Update on Locating the Undocumented and a Discussion on Judicial Avoidance of Race-Based Investigative Targeting in Constitutional Analysis, En San Diego Law Review, vol. 28, núm. 3, 1991, p. 501.

200 Ver Lopez-Mendoza, 468 U.S. 1032; ver también Verdugo-Urquidez, 494 U.S. 259.

201 Verdugo-Urquidez, 494 U.S. pp. 271-272.

202 Ídem.

203 Ibid, p. 271.

204 Ibid, p. 283.

205 Ibid, p. 286.

206 Verdugo-Urquidez, 494 U.S. p. 286.

207 Ibid, p. 283

208 Ibid p. 264.

209 Lopez-Mendoza, 468 U.S. p. 1035.

210 Ibid, p. 1046; Verdugo-Urquidez, 494 U.S. p. 272.

211 Verdugo-Urquidez, 494 U.S. p. 264.
} 
Gobierno fuera de las fronteras de los Estados Unidos ${ }^{212}$. El Juez Kennedy incluso declaró en su opinión concurrente que "si la búsqueda hubiera ocurrido en una residencia dentro de los Estados Unidos, no cabría duda de que se aplicaría la protección completa de la Cuarta Enmienda213."

Un tercer factor a considerar en un análisis de la Cuarta Enmienda es si el inmigrante indocumentado ha cometido crímenes y si su caso es civil o penal ${ }^{214}$. En este punto, es importante reflexionar sobre la misión del DHS y concentrarse en apuntar a los inmigrantes indocumentados que podrían estar vinculados al terrorismo o actividades delictivas en general ${ }^{215}$. La actividad delictiva es una prioridad para el DHS y, por ende, el DHS debería ser teóricamente más indulgente con los inmigrantes indocumentados involucrados en asuntos civiles especialmente- considerando sus limitados recursos 216 . Los tribunales también consideran la actividad criminal de un inmigrante indocumentado cuando determinan hasta qué punto extender las protecciones de la Cuarta Enmienda217. La Corte Suprema de López-Mendoza fue más simpática porque no invocaba la Cuarta Enmienda en un caso penal ni era sospechosa de un crimen ${ }^{218}$. LópezMendoza era un detenido de inmigración que se enfrentaba a la deportación y, por lo tanto, su caso era "puramente civil219." Sin embargo, la Corte Suprema de Verdugo-Urquidez vacilaba en fallar a favor de Verdugo-Urquidez, porque era sospechoso de contrabando de drogas y de participar en el asesinato de un agente de la DEA 220.

\section{Análisis}

Es un reto tratar de aplicar cualquiera de las pruebas o factores de la Cuarta Enmienda para determinar si el uso por parte del DHS del monitoreo de pulsera de tobillo GPS es constitucional porque la población de inmigrantes indocumentados es muy diversa. No hay un inmigrante indocumentado típico y sugerir lo contrario sería basar un análisis legal en estereotipos y desinformación. Sin embargo, para el propósito de este artículo, esta nota asume ciertas características compartidas basadas en los factores que el DHS pretende considerar al determinar quién usará los brazaletes de tobillo versus quién permanecerá en un centro de detención.

La aplicación de la ley de inmigración del DHS es una especie de sistema basado

212 Ibid, p. 266.

213 Ibid, p. 278.

214 Lopez-Mendoza, 468 U.S. p. 1038.

215 SUMMERILL, Joseph. Immigration and Customs Enforcement Introduces "Friendly" Federal Detention Standards and New, Softer Detention Facilities. En The Federal Lawyer, 2012, p. 46.

216 Ídem.

217 Ver Lopez-Mendoza, 468 U.S. 1032; ver también Verdugo-Urquidez, 494 U.S. 259.

218 Lopez-Mendoza, 468 U.S. p. 1038.

219 Ídem; Papst, supra note 51, p. 265.

220 Verdugo-Urquidez, 494 U.S. pp. 262-263. 
en prioridades debido a la limitación de recursos 221 . En consonancia con su misión, el DHS se centra en los inmigrantes indocumentados que representan una amenaza directa para la seguridad nacional, seguidos por los inmigrantes indocumentados que ingresaron al país con condenas penales como la trata de personas, el narcotráfico, la pornografía infantil, y otros crímenes graves ${ }^{222}$. Según Jennifer Elzea, una portavoz de ICE, los inmigrantes indocumentados a quienes se les permite salir de los centros de detención y se ven obligados a usar brazaletes de tobillo suelen ser "aquellos que no representan una amenaza para la seguridad pública ${ }^{223}$." El DHS también ha aclarado que inmigrantes indocumentados que son menores de 18 años, embarazadas, o que tengan problemas médicos significativos no se les emiten brazaletes de tobillo224.

Teniendo en cuenta el alcance del presupuesto del DHS y las limitaciones sobre quién puede usar los brazaletes de tobillo, es posible asumir algunas características compartidas entre los inmigrantes indocumentados que llevan estos brazaletes. Los inmigrantes indocumentados que están sujetos a los Programas Alternativos a la Detención, específicamente, monitoreando a través de los brazaletes de tobillo, son más (1) inmigrantes jóvenes de mediana edad, (2) sin antecedentes penales que (3) llegaron voluntariamente a los Estados Unidos. Con el fin de examinar si los programas de seguimiento de la pulsera de tobillo, tales como el actual programa RGV 250, son constitucionales, esta nota aplicará algunos de los tests de la Cuarta Enmienda más utilizados.

El alcance de las protecciones constitucionales otorgadas a los inmigrantes indocumentados sigue siendo una cuestión sin respuesta por parte de la Corte Suprema. Sin embargo, debido al hecho de que los inmigrantes indocumentados que usan brazaletes de tobillo no son criminales y están en los Estados Unidos voluntariamente, es posible asumir, de López-Mendoza y Verdugo-Urquidez, que tienen al menos las protecciones mínimas de la Cuarta Enmienda225.

\section{i. Modelo de delito de entrada}

El modelo de transgresión del Juez Scalia consiste en una prueba de dos partes que determina si ocurrió una violación constitucional226. En la primera parte, se pregunta si el Gobierno se ha inmiscuido físicamente en un área

221 FANDL, Kevin J. Immigration Posses: U.S. Immigration Law and Local Enforcement Practices. En Journal of Legislation, vol. 34, núm. 1, 2008, p. 36.

222 Ídem.

223 CALDWELL, Alicia A. DHS Is Using GPS-Enabled Ankle Bracelets To Track Immigrant Families Crossing The Border. MCGILL, 2014. http:/ /oppenheimer.mcgill.ca/DHS-Is-Using-GPS-EnabledAnkle?lang=fr.

224 http:/www.latimes.com/nation/immigration/la-na-immigrant-ankle-monitors-20150802story.html, Los Angeles Times. Consulta realizada el día 09 de diciembre de 2018.

225 Ver Lopez-Mendoza, 468 U.S. 1032; ver también Verdugo-Urquidez, 494 U.S. 259.

226 Jones, 132 S. Ct. p. 955 (citing United States v. Knotts, 460 U.S. 276, 286, (1983) (Brennan, J., concurring in judgment)). 
constitucionalmente protegida ${ }^{227}$. La segunda parte cuestiona si dicha intrusión fue con el propósito de obtener información ${ }^{228}$. A lo largo del análisis es útil tener en cuenta que la Cuarta Enmienda enumera la privacidad "en sus personas, casas, papeles y efectos" porque establece el alcance de lo que se considera un área constitucionalmente protegida ${ }^{229}$.

Los inmigrantes indocumentados están obligados a llevar los brazaletes de tobillo GPS durante largos períodos de tiempo y están siendo constantemente supervisados por el DHS230. Esto significa que los brazaletes de tobillo GPS no solo están en la persona de los inmigrantes indocumentados, sino que ingresan también en sus casas y efectos.

¿Acaso el Gobierno ha incurrido en una intrusión física en un área constitucionalmente protegida? Sí. ¿Se ha entrometido el Gobierno en un área protegida con el fin de obtener información? Sí.

\section{ii. Modelo de la privacidad: expectativa razonable del test de privacidad}

El test del modelo de privacidad es en realidad la prueba de la expectativa razonable de la Juez Harlan en Katz ${ }^{231}$. Bajo esta prueba, una violación de la Cuarta Enmienda ocurre cuando el Gobierno toma ciertas acciones intrusivas y una persona tenía una expectativa razonable de privacidad ${ }^{232}$. La prueba para determinar si había una expectativa razonable de privacidad es doble: (1) ¿Tiene una persona una expectativa subjetiva de privacidad? y (2) ¿Sería esa expectativa una que la sociedad reconocería como razonable ${ }^{233}$ ?

Los inmigrantes indocumentados que usan brazaletes de tobillo tienen una menor expectativa de privacidad que otras personas que viven en los Estados Unidos con un estatus migratorio legal porque ya entienden que el DHS está monitoreando cada movimiento. Sin embargo, los brazaletes de tobillo no evaporan todos los intereses de la privacidad por completo. A pesar de los brazaletes del tobillo, los inmigrantes indocumentados todavía pueden tener expectativas razonables de privacidad.

Tal vez lo más notable es que los inmigrantes indocumentados tienen una expectativa razonable de privacidad cuando están dentro de sus hogares. El GPS en los brazaletes de tobillo puede enviar señales a múltiples satélites y los satélites pueden triangular con precisión la ubicación del GPS a unos pocos pies o, a veces

\footnotetext{
227 Ídem.

228 Ídem.

229 Ibid, p. 949.

230 BURNETT, John. As Asylum Seekers Swap Prison Beds For Ankle Bracelets, Same Firm Profits, NPR (Nov. 13, 2015), http://www.npr.org/2015/11/13/455 790454/as-asylum-seekers-swap-prisonbeds-for-ankle-bracelets-same-firmprofits.

231 Katz, 389 U.S. p. 361 (Harlan, J., concurring).

232 Ídem.

233 Ídem.
} 
dentro de diez pulgadas234. Eso significa que DHS no sólo sería capaz de saber cuándo llegan a sus casas, sino también dónde exactamente estás en tu casa. El DHS podría aprender detalles íntimos, como cuándo está cocinando y duchándose. Los inmigrantes indocumentados probablemente tienen una expectativa subjetiva de privacidad que el DHS no será una presencia tan extrema y constante en sus hogares. Es probable que la sociedad reconozca esa expectativa como razonable porque la sociedad, así como los tribunales, reconoce que las búsquedas arbitrarias en el hogar de uno son un "mal principal" y que la Cuarta Enmienda tiene por objeto proteger la "santidad del hogar235."

\section{iii. Test de la teoría del mosaico}

La teoría del mosaico se aplica mejor a situaciones en las que hay vigilancia a largo plazo o tecnología avanzada, como un GPS, que puede transmitir una gran cantidad de información durante un largo período de tiempo. En este caso, el DHS utiliza tanto la vigilancia a largo plazo como la tecnología avanzada. La teoría del mosaico afirma que,

"Los intereses de privacidad, como los protegidos bajo la Cuarta Enmienda, deben ser protegidos de una manera que proteja contra colecciones de pequeños fragmentos de información que individualmente no pueden ser particularmente reveladores, pero que en conjunto pueden revelar mucho236."

Bajo la teoría del mosaico, una colección de movimientos individuales de una persona puede crear antecedentes donde todo revela "más que los movimientos individuales que comprende 237 ." Por ejemplo, si los funcionarios encargados de hacer cumplir la ley aprenden que una persona visitó un café específico un domingo y ordenó un café pequeño, entonces no podrían aprender mucho aunque la vigilancia fuera detallada. Si la vigilancia está en curso y los funcionarios del cumplimiento de la ley saben que esta persona visita la misma cafetería y ordena el mismo café todos los domingos, entonces habrían aprendido sobre los hábitos o patrones de esa persona ${ }^{238}$.

Si se aplica esta prueba, es probable que el programa de pulsera de tobillo DHS sea considerado inconstitucional bajo la Cuarta Enmienda. El GPS en los brazaletes del tobillo es exacto y puede divulgar la información altamente detallada. Los inmigrantes indocumentados también están obligados a llevar los brazaletes a lo largo del día, cada día, durante largos períodos de tiempo. No solo los brazaletes

234 MILLER, Jordan. "New Age Tracking Technologies in the Post-United States v. Jones Environment: The Need for Model Legislation". En Creighton Law Review, vol. 48, núm. 3, 2015, p. 561.

235 EVANS, Katherine. The Ice Storm in U.S. Homes: An Urgent Call for Policy Change. En N.Y.U. Review of Law \& Social Change, vol. 33, núm. 4, 2009, pp. 561-611.

236 ARCILA, Fabio. GPS Tracking Out of Fourth Amendment Dead Ends: United States v. Jones and the Katz Conundrum. En North Carolina Law Review, vol. 91, núm. 1, 2012, p. 12.

237 Ibid, p. 13.

238 Ídem. 
de tobillo GPS dan a DHS una imagen completa de la vida privada de estos inmigrantes indocumentados, sino que también dan una imagen extremadamente precisa e íntima.

\section{iv. Test de ponderación}

El test de ponderación se aplica típicamente en el contexto civil para evaluar la "razonabilidad" de los funcionarios encargados de hacer cumplir la ley en relación con la Cuarta Enmienda ${ }^{239}$. El test funciona "equilibrando el interés legítimo de la aplicación de la ley con el nivel de intrusión 240 ." Antes de aplicar el test, los inmigrantes indocumentados deben tener un interés de privacidad de la Cuarta Enmienda ${ }^{241}$. Los inmigrantes indocumentados que llevan brazaletes de tobillo, como mínimo, tienen intereses de privacidad de Cuarta Enmienda en su persona y su hogar.

Los funcionarios encargados de hacer cumplir la ley en este caso son de la agencia del DHS. El interés del DHS es prevenir los ataques terroristas y reducir la vulnerabilidad de los Estados Unidos al terrorismo ${ }^{242}$. Inicialmente, parece que el DHS tiene un gran interés, pero después de algunos análisis, sus intereses no son tan importantes. Los inmigrantes indocumentados que llevan brazaletes de tobillo no tienen antecedentes penales, por lo que incluso se les permitió salir de los centros de detención y entrar en el programa de vigilancia. DHS probablemente no está preocupado de que los inmigrantes indocumentados que llevan los brazaletes de tobillo son el tipo de personas que representan una amenaza terrorista a los Estados Unidos o que están haciendo vulnerable a los Estados Unidos. Así, DHS tiene un interés, pero no un interés significativo.

Los inmigrantes indocumentados que llevan los brazaletes de tobillo tienen un interés en tener privacidad en su hogar y su persona. El interés por la privacidad de los inmigrantes indocumentados se refuerza aún más porque el hogar siempre ha recibido protección especial por la Cuarta Enmienda ${ }^{243}$. Teniendo en cuenta que los brazaletes del tobillo están encendidas en todo momento y un GPS puede retransmitir una información extremadamente precisa, el interés de la privacidad de los inmigrantes indocumentados es mucho mayor que el interés del DHS.

Después de equilibrar los intereses del DHS y los intereses de los inmigrantes indocumentados, los intereses de los inmigrantes indocumentados inclinan la balanza. Los programas de monitoreo a través de brazaletes de tobillo se considerarán búsquedas no razonables bajo la Cuarta Enmienda.

239 MILLER, Jordan. “New Age Tracking Technologies in the Post-United States v. Jones Environment: The Need for Model Legislation". En Creighton Law Review, vol. 48, núm. 3, 2015, pp. 1014-1015.

240 Îdem.

241 Ídem.

242 Homeland Security Act of $2002 \S 101$.

243 Evans, supra note 235, p. 580. 


\section{v. Evaluando los resultados}

Los programas de monitoreo de pulsera de tobillo del DHS son inconstitucionales bajo el modelo de delito de entrada, el modelo de privacidad, la teoría del mosaico, y el test de ponderación. Los intereses del DHS en monitorear continuamente a los inmigrantes indocumentados con brazaletes de tobillo no se comparan con los sustanciales intereses de privacidad de los inmigrantes indocumentados bajo la Cuarta Enmienda.

En primer lugar, los inmigrantes indocumentados que están siendo sometidos al monitoreo de pulsera de tobillo no tienen antecedentes penales y no representan una seria amenaza para los Estados Unidos. En segundo lugar, los inmigrantes indocumentados que llevaban brazaletes de tobillo del DHS entraron voluntariamente en los Estados Unidos. En tercer lugar, y quizás lo más importante, estos inmigrantes indocumentados han creado una conexión sustancial con este país o pronto harán una conexión sustancial ya que decidieron cumplir con la ley de los Estados Unidos al usar los brazaletes de tobillo.

El DHS podría tener un mejor argumento a favor de sus programas de monitoreo de tobillo si el monitoreo fuera más limitado. Por ejemplo, el DHS podría vigilar a los inmigrantes indocumentados solo si abandonan la casa o tal vez durante ciertas horas del día. Sin embargo, el monitoreo continuo revela demasiadas descripciones íntimas que resultan en búsquedas no razonables bajo la Cuarta Enmienda.

Hay poca claridad en la Constitución acerca de los inmigrantes indocumentados, pero al menos una cosa siempre ha sido clara. La Cuarta Enmienda tenía por objeto proteger el hogar ${ }^{244}$. El DHS es la segunda fuerza de investigación más grande del gobierno federal y no debe concentrar sus recursos en el monitoreo de inmigrantes indocumentados de una manera que menoscabe una verdad constitucional ampliamente reconocida ${ }^{245}$.

\section{Conclusión}

El DHS ha estado violando consistentemente los derechos constitucionales de la Cuarta Enmienda de los inmigrantes indocumentados con sus prácticas intrusivas de la policía durante años, en nombre de la "aplicación de las normas de inmigración 246 ." Hasta que la Corte Suprema responda directamente a la pregunta de cuáles son los derechos de la Cuarta Enmienda a los inmigrantes indocumentados, no está claro qué derechos constitucionales se encuentran garantizados a los inmigrantes indocumentados. La falta de claridad en cuanto a

244 MILLER, Jordan. "New Age Tracking Technologies in the Post-United States v. Jones Environment: The Need for Model Legislation". En Creighton Law Review, vol. 48, núm. 3, 2015, p. 1008.

245 CADE, Jason A. Policing the Immigration Police: Ice Prosecutorial Discretion and the Fourth Amendment. En Columbia Law Review, vol. 113, (2013), pp. 180-203.

246 Ídem. 
los derechos constitucionales de los inmigrantes indocumentados podría ser una señal de que Estados Unidos no está dispuesto a abolir las distinciones ciudadanas y no ciudadanas ${ }^{247}$. Sin embargo, si Estados Unidos no está dispuesto a abolir las distinciones basadas en el estatus de inmigración, entonces debería por lo menos garantizar un sistema de protecciones suficientes para los derechos personales ${ }^{248}$.

Los inmigrantes indocumentados que están siendo sometidos a la vigilancia del tobillo GPS por el DHS ya han sido clasificados como no amenazantes para la seguridad nacional. De hecho, esto se debe a que estos inmigrantes indocumentados no representan una amenaza y no tienen registros criminales de que están siendo liberados de los centros de detención. Por su buen comportamiento y registros limpios, los inmigrantes indocumentados son recompensados por el DHS con una liberación de los centros de detención y una sentencia de monitoreo constante por un período de tiempo indeterminado.

Esta práctica de "intercambiar camas de prisión por brazaletes de tobillo" está intercambiando efectivamente un centro de detención por un tipo diferente de centro de detención ${ }^{249}$. Los inmigrantes indocumentados informan que vivir fuera de un centro de detención con monitoreo de pulsera de tobillo no es muy diferente a vivir en un centro de detención ${ }^{250}$. Fresvinda Ponce, una madre de 41 años de Camayagua, Honduras, describe su experiencia al decir: "ahora me siento libre, pero al mismo tiempo creo que todavía no estoy libre, siempre y cuando lleve este grillete, no estoy contenta. Me siento aún como prisionera ${ }^{251 . " ~ P o n c e ~ e s t a ́ ~}$ condenada a vivir psicológica y físicamente con su infelicidad durante un período de tiempo aparentemente interminable, porque ni siquiera sabe cuándo puede quitarse la pulsera del tobillo252.

Ponce no está sola. Otros inmigrantes indocumentados han informado que también se sienten frustrados y desmoralizados debido a los programas de vigilancia del tobillo ${ }^{253}$. Por ejemplo, Carolina Menjivar, una hondureña de 28 años de edad, afirma que "[la pulsera del tobillo] me da vergüenza, porque solo los ponen en delincuentes, y yo no soy una criminal todavía 254 ." Los defensores de los inmigrantes han declarado que debido a estas experiencias, los monitores de tobillo no son una "verdadera alternativa a la detención, sino más bien una forma de ampliar el alcance de la detención y castigar aún más a los inmigrantes que

247 ROMERO, Victor C. The Domestic Fourth Amendment Rights of Undocumented Immigrants: On Gutierrez and the Tort Law/Immigration Law Parallel. En PennState Law, vol. 35, 2000, pp. 57-101. 248 Ídem.

249 MILLER, Jordan. "New Age Tracking Technologies in the Post-United States v. Jones Environment: The Need for Model Legislation". En Creighton Law Review, vol. 48, núm. 3, 2015.

250 Ídem.

251 Ídem.

252 Ídem.

253 Ídem.

254 Ídem. 
viven ilegalmente en los Estados Unidos $255 . "$

Es injusto tratar a los inmigrantes indocumentados como criminales sin derechos constitucionales. Los inmigrantes indocumentados entran en los Estados Unidos como extranjeros, pero forman conexiones más que suficientes con el país de tal manera que tienen derecho a por lo menos las protecciones mínimas de la Cuarta Enmienda. Después de evaluar la Cuarta Enmienda, este artículo concluye que basándose en el modelo de delito de entrada, el modelo de privacidad, la teoría del mosaico y el test de ponderación, los programas de monitoreo de la pulsera de tobillo del DHS son inconstitucionales.

255 http://latinousa.org/2015/10/23/why-are-immigrant-mothers-wearing-ankle-monitors/, Latino USA.

Consulta realizada el día 09 de diciembre de 2018. 